\title{
DA SINTOMATOLOGIA DE MODELO JUNGUIANO À CRÍTICA PORTADORA DE COORDENADAS TRANSCENDENTAIS: UMA Leitura a Respeito do SaCher-Masoch de Deleuze
}

\author{
Flávio Luiz de Castro Freitas ${ }^{1}$ \\ Luciano da Silva Façanha
}

\begin{abstract}
Resumo: O objetivo geral do presente trabalho consiste em explicitar o percurso entre duas leituras que Gilles Deleuze realiza acerca da obra de Sacher-Masoch, na década de 60 do século XX. A primeira leitura concerne ao artigo de 1961, denominado "De Sacher-Masoch ao masoquismo". A segunda leitura diz respeito ao livro de 1967, intitulado de Sacher-Masoch - o frio e o cruel. Postula-se que a relação entre esses dois momentos é constituída por um processo de radicalização transcendental da parte de Deleuze, o qual vai da sintomatologia de modelo junguiano até alcançar a crítica transcendental.
\end{abstract}

Palavras-chave: Deleuze. Sacher-Masoch. Jung. Sintomatologia. Transcendental.

\section{INTRODUÇÃO}

O objetivo do presente trabalho consiste em explicitar o percurso que pode ser localizado entre duas leituras realizadas por Gilles Deleuze acerca da obra de Sacher-Masoch, durante a década de 60 do século XX. A primeira leitura concerne ao artigo de 1961, intitulado "De Sacher-Masoch ao masoquismo". A segunda leitura, por sua vez, diz respeito ao livro de 1967, cujo título é Sacher-Masoch - o frio e o cruel. É apropriado lembrarmos que essas leituras de Deleuze referentes à obra de Sacher-Masoch devem ser

\footnotetext{
${ }^{1}$ Professor Doutor do Curso de Licenciatura em Ciências Humanas e do Programa de Pós-Graduação em Cultura e Sociedade da Universidade Federal do Maranhāo (UFMA), MA - Brasil. (iD) https:// orcid.org/0000-0002-7648-0341. E-mail: f_lcf@hotmail.com.

2 Professor Doutor do Departamento de Filosofia e do Programa de Pós-Graduação em Cultura e Sociedade da Universidade Federal do Maranhão (UFMA), MA - Brasil. (D) https://orcid.org/00000003-1178-4018. E-mail: lucianosfacanha@hotmail.com.
}

http://dx.doi.org/10.1590/0101-3173.2020.v43n4.11.p183 
consideradas no contexto das relaçóes entre filosofia, literatura e psicanálise. Especificamente, naquilo que corresponde à questáo acerca da serventia e do funcionamento da literatura.

Dessa maneira, levando-se em consideração esse contexto, aceitamos a hipótese interpretativa voltada para preconizar que a serventia e o funcionamento da literatura, para Deleuze, consistem em se desgastar, se enlouquecer, se desorganizar, com o fito de liberar os devires singulares e impessoais do primado do pai, do "nome do Pai" e da paixão pelo significante (ALLIEZ, 2007, p. 225-236). Isso ocorre precisamente no caso de SacherMasoch, uma vez que pode ser compreendido como uma linha que culmina na política deleuziana, a qual está entre a clínica literária e a crítica à psicanálise.

Com isso, enfatizamos as duas leituras da década de 60 do século XX, pois ambas estão voltadas para expor as relaçôes críticas entre sintomatologia, masoquismo e psicanálise (DOSSE, 2010). Todavia, existe ainda uma terceira leitura que Deleuze faz sobre a obra de Sacher-Masoch. Essa terceira leitura integra a coletânea intitulada Crítica e Clínica, que foi publicada em 1993. O título desse terceiro momento é Reapresentação de Sacher-Masoch. Nessa ocasião, Deleuze investiga os elementos éticos existentes na obra de SacherMasoch. Em função disso, concordamos com a ideia de que, em se tratando da obra de Sacher-Masoch, o pensamento de Deleuze se move da sintomatologia até chegar à ética (SANTIAGO, 2014). Porém, em sintonia com os limites estabelecidos pelo objetivo do presente artigo, trataremos do percurso de Deleuze em relação às duas primeiras leituras.

Quanto às duas leituras realizadas durante a década de 60 do século $\mathrm{XX}$, é necessário destacar que elas também são a expressão da porta de entrada para o saber psicanalítico dentro da obra de Deleuze, visto que o tema da sintomatologia constitui o núcleo do início da problematização crítica empreendida por esse autor:

Não me permitiria falar de psicanálise e de psiquiatria se não se tratasse de um problema de sintomatologia. Ora, a sintomatologia situa-se quase que no exterior da medicina, num ponto neutro, um ponto zero, onde os artistas e os filósofos e os médicos e os doentes podem se encontrar (DELEUZE, 2006, p. 174).

Dessa maneira, com o fito de alcançar o objetivo proposto, postulamos, enquanto hipótese interpretativa, que a relação entre os dois primeiros 
momentos é constituída por um processo de radicalização transcendental, por parte do pensamento de Deleuze. Isso significa que, de um ponto de vista crítico, Deleuze está problematizando uma Imagem do pensamento marcada pelo modelo empírico-material, o qual, no seu entendimento, está inserido no coração do pensamento psicanalítico. Tamanha problematização movimenta o percurso do pensamento de Deleuze em torno da obra de Sacher-Masoch, pois, em "De Sacher-Masoch ao masoquismo", de 1961, Deleuze propóe um modelo simbólico, inspirado em Jung, à revelia do modelo empírico-material adotado por Freud.

Ainda enquanto elemento integrante de nossa hipótese de leitura, entendemos que o tema da sintomatologia na obra de Deleuze, especificamenete na década de 60 do século XX, possa ser dividido em duas partes. A primeira parte está presente no artigo de 1961 e corresponde à sintomatologia junguiana. Por sua vez, a segunda parte figura no livro de 1967 e equivale à crítica portadora de coordenadas transcendentais.

Assim, compreendemos que a segunda parte da sintomatologia seja a própria crítica transcedental, a qual decorre de possíveis limites do momento sintomatológico de modelo junguiano, pois, embora esse modelo seja dotado de criatividade e pertinência filosófica, ainda não expóe de forma clara e isenta de ambiguidade, no texto de 1961, uma problematização marcadamente transcedental, mesmo que ocorra uma força intensiva de mobilização e demolição do pensamento. Essa problemzação transcedental será devidamente exposta e a ambguidade resolvida, naquilo que tange aos princípios, no livro de 1967, destacadamente a distinção entre o enpírico e o transcedental.

Consequentemente, isso significa que, no livro de 1967, SacherMasoch - o frio e o cruel, Deleuze se propóe efetuar uma interpretação crítica e transcendental do texto Além do princípio de prazer de Sigmund Freud. Nessa interpretação, Deleuze evoca uma importante questão: em que medida o prazer pode ser considerado um princípio?

O itinerário adotado por Deleuze para desenvolver esse problema o conduz ao tema da fundação do prazer enquanto princípio e, eventualmente, da fundação do próprio pensamento, demarcando, por fim, uma mudança em relação ao texto de 1961, já que as coordenadas transcendentais substituem o modelo junguiano.

Com base nisso, para desenvolver a hipótese de leitura apresentada, nosso percurso está dividido em quatro partes, dentre as quais destacamos 
primordialmente as partes dois e três, visto que elas concernem, respectivamente, à sintomatologia de modelo junguiano e à crítica portadora de coordenadas transcendentais.

Em "A sintomatologia de modelo junguiano", identificamos o percurso de Deleuze, no artigo cujo título é "De Sacher-Masoch ao masoquismo", de 1961. Nossa exposição destaca as características do masoquismo, para Deleuze, através da obra de Sacher-Masoch, bem como frisa sua eventual sistematização crítica, por meio do pensamento de Jung.

Já em "A crítica de coordenadas transcendentais", a qual está presente no livro Sacher-Masoch - o frio e o cruel de 1967, caracterizamos o projeto deleuziano que está voltado para a construção de uma instância transcendental heterogênea e exterior capaz de fundar o pensamento e fundamentar a vida psíquica, vindo a sustentar a regulação empírica da mesma.

\section{A sintomatologia de modelo junguiano}

A sintomatologia de modelo junguiano consiste no uso que Deleuze faz do pensamento de Jung, para interpretar e sistematizar a obra literária de Sacher-Masoch. Ocorre que essa sistematização é composta por uma crítica à psicanálise, em particular ao tema da unidade da entidade sadomasoquista.

Desse modo, o problema central do artigo intitulado "De SacherMasoch ao masoquismo", de 1961 está voltado para caracterizar uma sintomatologia do masoquismo, a partir da obra de Sacher-Masoch, pois, para Deleuze, a obra desse escritor fornece um modelo rico e preciso acerca desse tema (DELEUZE, 1992). Tamanha riqueza e precisão estão relacionadas às características formais que são identificadas pelo trabalho de Deleuze.

O pressuposto contido nesse projeto sintomatológico sustenta que não há complementariedade entre as exigências do sadismo e do masoquismo, pois seus meios e seus rituais diferem inteiramente. Além disso, a sintomatologia é apresentada como sendo uma atividade especificamente anterior e primeira com respeito à etiologia, que, por sua vez, necessita da construção de uma boa sintomatologia para evitar direçóes inúteis ou mesmo inexatas.

La spécificité symptomatologique est première; la spécificité de l'agent causal, tourjours seconde et relative. On regrettera donc, dans le cas de Masoch, que les spécialistes de masochisme se soient si peu intéressés au contenu de son ouvre. En général ils se sont contentés d'une 
symptomatologie beaucoup moins précise, beaucoup plus confuse que celle qu'on trouve chez Masoch lui-même (DELEUZE, 2015/1961, p. 170).

Com isso, no início do percurso ou linha argumentativa do trabalho de 1961, Deleuze apresenta a sintomatologia, com base em três importantes elementos pertinentes ao masoquismo, a partir da obra de Sacher-Masoch: o paradoxo culturalista e estético, o gosto pelo contrato e a perspectiva histórica estranha. Para atender a nosso propósito, trataremos dos dois últimos.

Deleuze considera o gosto pelo contrato como sendo a característica formal do masoquismo por excelência, bem como seu principal traço distintivo. Em termos deleuzianos, não há masoquismo sem contrato, o qual está necessariamente projetado na relação do homem com uma mulher dominante.

\begin{abstract}
- Ah, o senhor ainda não me conhece, pois saiba, eu realmente sou cruel no sentido gozoso que lhe tem esta palavra -, e acaso não teria o direito de sê-lo? O homem é o cobiçoso, a mulher, a cobiçada, eis aí a vantagem plena e crucial da mulher. A natureza dotou o homem de paixão, e a mulher que náo souber submetê-lo, fazer dele seu escravo, seu brinquedo e, ao final, traí-lo com um riso estampado no rosto, não será mulher inteligente (SACHER-MASOCH, 2015, p. 22).
\end{abstract}

Ademais, o contrato tem uma função que depende estreitamente das sociedades patriarcais, ou seja, ele é constituído para exprimir e até mesmo justificar aquilo que há de não material, de espiritual ou de instituído, nas relaçôes de autoridade e associação, inclusive entre um pai e seus filhos. No entanto, de acordo com Deleuze, existe uma ligação material que une o homem à mulher e as crianças às mães. Essa ligação, por natureza, é rebelde com respeito à autoridade patriarcal expressa no contrato. E tecnicamente é denominada de "ctônica", que significa um elo de ordem subterrâneo e disforme, o qual é oposto às formas estabelecidas, como no caso do antropomorfismo das divindades gregas.

Nesse sentido, do ponto de vista patriarcal, quando uma mulher entra ou passa a fazer parte do contrato, ocorre o reconhecimento societário de sua dependência em relação ao homem. Entretanto, para Deleuze, o contrato de Masoch inverte tudo isso, pois ele exprime a predominância material da mulher e a superioridade do princípio maternal. Além disso, Deleuze mostra 
que, caso adotemos como pressuposto a fundação de uma sociedade viril, o masoquista ultrapassa o movimento pelo qual o contrato evolui no tempo.

Tal movimento é composto pelos seguintes elementos: uma limitação temporal, a não intervenção de terceiros e a exclusão de certas propriedades inalienáveis (como a vida). Esse movimento também é formado por processos de âmbito social de postulação de sua própria eternidade, enfatizando seu direito de morte sobre todos os súditos integrantes dessa sociedade.

Em seguida, Deleuze detalha a terceira característica do masoquismo: a perspectiva histórica estranha. Semelhante perspectiva é uma cosmologia arquetípica dotada de consequências antropológicas. Nessa perspectiva histórica estranha, Masoch faz frequentemente alusão a uma época da "bela Natureza" e a um mundo arcaico presidido por Vênus-Afrodite, onde a relação fugaz da mulher e do homem tem como única lei o prazer entre parceiros iguais.

Nesse contexto, as heroínas de Masoch não são dotadas de uma natureza sádica, mas de uma natureza pagã, antiga e heroica. Deleuze discorre que a "bela Natureza" foi desequilibrada por uma catástrofe climática ou por um colapso glacial, fazendo com que a lei natural se recolhesse no interior ao seio materno como o princípio feminino que conserva um pouco de calor.

Em função disso, os homens transformaram-se nas crianças da reflexão. $\mathrm{Na}$ tentativa de cultivar alguma espiritualidade autônoma, os homens terminam por perder sua própria natureza ou suas almas. Dentro dessa cosmologia arquetípica, as peles que envolvem as mulheres de Masoch possuem vários significados. Contudo, o texto de Deleuze fornece a impressáo de que todos os significados remetem ao tema do feminino.

Além disso, para Deleuze, existe na narrativa cosmológica e arquetípica de Masoch uma correspondência entre a lei de natureza e o princípio materno, cujo rigor é testemunhado por inúmeras divindades femininas, ctônicas e lunares, tais quais grandes caçadoras, poderosas amazonas e as cortesãs dominantes. Entretanto, o gélido triunfo equivalente à virilidade da sociedade patriarcal expulsa cosmologicamente o princípio materno, conhecido também como "L'Anima", e promove a instauração de um mundo no qual as alianças espirituais prevalecem sobre a ligação materna de sangue. Segundo Deleuze, havia um mundo romano, depois cristão, onde Vênus não tem mais lugar. 
Ocorre que, para trazer novamente à tona o princípio materno, L'Anima, é necessário adotar como ponto de partida as próprias estruturas patriarcais. De acordo com Deleuze, no texto de 1961, o verdadeiro homem será fruto dos rigores de uma ginecocracia restaurada através de uma mulher potente, capaz de desviar as estruturas do patriarcado. $\mathrm{Na}$ fantasia regressiva, a relação doméstica e a relação conjugal passam ao benefício da "Mulher terrível" ou da "Mãe devorante": "- Não posso negar - eu disse -, para o homem não há nada que o excite mais do que a imagem de uma despótica mulher bela, voluptuosa e cruel, que dispóe de seus favoritos de maneira atrevida e desconsiderada, a seu bel-prazer." (SACHER-MASOCH, 2015, p. 23).

Nesse ponto é importante realizar uma relevante elucidação dentro dos limites de nosso trabalho. Até o presente momento, reconstruímos o percurso ou linha argumentativa de Deleuze, no artigo de 1961, "De Sacher-Masoch ao masoquismo". Frisamos que semelhante percurso diz respeito à sintomatologia que Deleuze identifica em Masoch acerca do masoquismo e, em particular, tratamos das três características inerentes ao mesmo.

A partir dessas características, Deleuze organiza e prepara sua crítica à interpretaçâo de Reik acerca do masoquismo. Todavia, para efetivar esse intento, Deleuze faz uso de um aliado adicional ao lado de Sacher-Masoch, isto é, Jung, especificamente, nesse primeiro momento, da noção de inconsciente coletivo:

O inconsciente coletivo é tudo, menos um sistema pessoal encapsulado. É objetividade ampla como o mundo e aberta ao mundo. Eu sou o objeto de todos os sujeitos, numa total inversão de minha consciência habitual, em que sempre sou sujeito que tem objetos. Lá eu estou na mais direta ligação com o mundo, de forma que facilmente esqueço quem sou na realidade. "Perdido em si mesmo" é uma boa expressão para caracterizar este estado. Este si-mesmo, porém, é o mundo, ou melhor, um mundo, se uma consciência pudesse vê-lo. Por isso, devemos saber quem somos (JUNG, 2000, p. 32).

Deleuze, metodologicamente, elabora uma crítica minuciosa contra as interpretaçóes freudianas. Essa crítica é composta e operacionalizada pela relação que Deleuze estabelece, em seu texto, entre Sacher-Masoch e Jung, embora desenvolva uma estranha e consistente argumentação com base na sintomatologia que ele atribui a Sacher-Masoch: 
Qu'il y ait des couches de l' inconsciente très différentes, d'origine et de valeur inégales, suscitant des régressions qui diffèrent en nature, ayant entre elles des rapports d'opposition, de compensation et de réorganisation: ce principe cher à Jung ne fut reconnu par Freud, parce que celui-ci réduisait l'inconscient au simple fait de désirer (DELEUZE, 2015, p. 174).

Deleuze faz uso do conceito de inconsciente coletivo de Jung para sustentar sua posição. A tese de Jung acerca do inconsciente coletivo preconiza que o próprio inconsciente é dotado de duas camadas:

Uma camada mais ou menos superficial do inconsciente é indubitavelmente pessoal. Nós a denominamos de inconsciente pessoal. Este, porém, repousa sobre uma camada mais profunda, que já não tem sua origem em experiências ou aquisições pessoais, sendo inata. Esta camada mais profunda é o que chamamos inconsciente coletivo. Eu optei pelo termo 'coletivo' pelo fato de o inconsciente não ser de natureza individual, mas universal; isto é, contrariamente à psique pessoal ele possui conteúdos e modos de comportamento, os quais são 'cum grano salis' os mesmos em toda parte e em todos os indivíduos. Em outras palavras, são idênticos em todos os seres humanos, constituindo, portanto, um substrato psíquico comum de natureza psíquica suprapessoal que existe em cada indivíduo (JUNG. 2000, p. 15).

A primeira delas é constituída por conteúdos individuais (pessoais) e portadora de certa superficialidade. A segunda delas, o inconsciente coletivo, é a camada mais profunda, impessoal e composta exclusivamente por arquétipos:

Uma existência psíquica só pode ser reconhecida pela presença de conteúdos capazes de serem conscientizados. Só podemos falar, portanto, de um inconsciente na medida em que comprovarmos os seus conteúdos. Os conteúdos do inconsciente pessoal são principalmente os complexos de tonalidade emocional, que constituem a intimidade pessoal da vida anímica. Os conteúdos do inconsciente coletivo, por outro lado, são chamados arquétipos (JUNG, 2000, p. 16).

Nos termos de Jung, os conteúdos do inconsciente pessoal outrora já estiveram de alguma maneira na consciência e foram expulsos da mesma, via repressáo ou recalque, culminando numa série ou conjunto de complexos. Por sua vez, os conteúdos do inconsciente coletivo não foram adquiridos de forma pessoal, no entanto, sua aquisição ocorre mediante a herança simbólica 
geral da humanidade e não através da hereditariedade individual e biológica de cada um:

O inconsciente coletivo é uma parte da psique que pode distinguirse de um inconsciente pessoal pelo fato de que náo deve sua existência à experiência pessoal, não sendo, portanto, uma aquisição pessoal. Enquanto o inconsciente pessoal é constituído essencialmente de conteúdos que já foram conscientes e, no entanto, desapareceram da consciência por terem sido esquecidos ou reprimidos, os conteúdos do inconsciente coletivo nunca estiveram na consciência e, portanto, náo foram adquiridos individualmente, mas devem sua existência apenas à hereditaríedade. Enquanto o inconsciente pessoal consiste em sua maior parte de complexos, o conteúdo do inconsciente coletivo é constituído essencialmente de arquétipos (JUNG, 2000, p. 53).

Os arquétipos são certos elementos estruturais e coletivos da alma humana aos quais correspondem tipos mitológicos e fantasias de caráter impessoal que não podem ser atribuídas à vivência de um passado individual. São formas sem propriamente conteúdo fixo, as quais estão presentes em todo o tempo e em todo o lugar, cuja expressão primeira é sempre metafórica.

É prudente lembrar que existem tantos arquétipos quantas situaçôes ou vivências ocorrem na vida humana, contudo, é possível destacar três deles: "animus" (imagem do masculino), "anima" (imagem do feminino) e o "simesmo" (selbst), o qual é equivalente ao centro da personalidade.

Desse modo, é possível encontrar, em "De Sacher-Masoch ao masoquismo", uma correspondência direta entre o princípio materno e a "L'Anima”, isto é, a imagem do feminino que foi acima mencionada. Em certo sentido, Deleuze lê e sistematiza Sacher-Masoch através de Jung.

Como consequência disso, Deleuze advoga que, em algumas ocasiōes, presenciamos relaçốes da consciência com as camadas superficiais do inconsciente, cujo propósito consiste em manter em xeque a camada mais profunda, que é composta pelo vínculo de sangue com a imagem do feminino.

Assim, a sintomatologia exposta por Deleuze em "De Sacher-Masoch ao masoquismo" pode ser considerada psicanalítica e literária, bem como portadora de contornos filosóficos, uma vez que faz uso de Sacher-Masoch e Jung, a fim de criticar Reik. Logo, é cabível ser denominada de sintomatologia junguiana, no contexto de uma leitura voltada para a sistematização da obra de Sacher-Masoch. 
Seguindo essa linha de seu argumento ou percurso, Deleuze propóe que falta à psicanálise, em particular a Freud, conhecer o papel das imagens originais, já que elas são explicadas exclusivamente por si mesmas, sem necessitar recorrer a qualquer outro tipo de recurso. As imagens são, por sua vez, o termo da regressão e o princípio de interpretação dos acontecimentos em si mesmos.

Os símbolos não se deixam compor, nem mesmo se permitem reduzir. Pelo contrário, eles são a regra última para a composição dos desejos e de seus objetos, eles formam os únicos dados irredutíveis do inconsciente. De acordo com Deleuze, o dado irredutível do inconsciente é o símbolo em si mesmo, ou melhor, tudo é símbolo no inconsciente, seja a morte, seja a sexualidade: "En vérité, tout est symbole dans l'inconsciente: la sexualiaté, la mort, non moins que le reste." (DELEUZE, 2015/1961, p. 180).

Nesses termos, a morte deve ser compreendida como uma morte simbólica, e o retorno à matéria, enquanto um retorno simbólico. As pulsóes são apenas as percepçôes internas das imagens originais apreendidas tais quais elas estão, nas diversas camadas do inconsciente. Então, o masoquismo é a percepçáo da imagem materna ou da mãe devorante.

O fundo desse aspecto da crítica de Deleuze em relação à psicanálise consiste no esboço de uma recusa à primazia do modelo material e empírico, para investigar o fenômeno do psiquismo. Utilizamos o termo "esboço", pois a fundamentação crítica estará desenvolvida com maior acuidade em SacherMasoch - o frio e o cruel, de 1967, e no capítulo 2 de Diferença e repetição, de 1968 (FREITAS, 2016). Para Deleuze, a sintomatologia junguiana postula o predomínio do modelo pautado nas imagens e nos símbolos, à revelia do modelo material e empírico.

Essa sintomatologia de inspiração junguiana pode ser compreendida como uma crítica estética à psicanálise. Contudo, baseada na própria psicanálise e expressando uma ambiguidade em relaçáo a esse saber. Essa ambiguidade ainda não é suficiente para sustentar um modelo de investigação filosófica para o psiquismo alicerçado nas imagens e nos símbolos, visto que não estão colocadas as condiçóes para o exercício de uma densidade especulativa, no âmbito transcendental, capaz de atuar enquanto fundamento crítico da própria seara empírica. 


\section{A Crítica PORTADORa DE COORDENADAS TRANSCENDENTAIS}

Assim, seguindo nossa linha argumentativa, para não nos extraviarmos do objetivo geral do presente artigo, é conveniente e necessário reafirmá-lo: explicitar o percurso que pode ser localizado entre duas leituras realizadas por Gilles Deleuze, acerca da obra de Sacher-Masoch, durante a década de 60 do século XX. Ora, entendemos como hipótese interpretativa, voltada para desenvolver esse objetivo geral, que essas leituras apresentadas por Deleuze sobre a obra de Sacher-Masoch equivalem ao tema da sintomatologia. No entanto, entendemos que o percurso de Deleuze a propósito da sintomatologia masoquiana também possa ser dividido em duas partes: sintomatologia junguiana e crítica portadora de coordenadas transcendentais.

Nesse sentido, a primeira parte deste trabalho foi direcionada para expor os argumentos pertinentes à sintomatologia de modelo junguiano, a qual nos conduziu a uma questão: qual é a natureza do movimento realizado pelo pensamento de Deleuze, de sorte a despedir-se e despir-se da sintomatologia de modelo junguiano e migrar para a crítica portadora de coordenadas transcendentais? Ou, dito de outro modo: por que a sintomatologia sofre uma transformaçáo em seu interior?

Entendemos que Deleuze tenha identificado limites de fundamentação filosófica para a sintomatologia de modelo junguiano e se mova na direção de contornar esses limites. Assim, semelhante sintomatologia não é capaz de fundar a si mesma, isto é, de investigar e buscar pelos seus próprios pressupostos, princípios e fundamentos. $\mathrm{Na}$ verdade, ela sequer elabora esse tipo de problema.

Isso significa que a sintomatologia de modelo junguiano náo realiza um movimento crítico, problematizador e circular em torno de si mesma, pois ela está de imediato se colocando como uma alternativa às coordenadas do modelo empírico-material, o qual repousa no cerne da interpretação freudiana.

Se a sintomatologia de modelo junguiano não é propriamente uma Imagem moral do pensamento, então ela é minimamente limitada, ao tentar problematizar o modelo empírico-transcendental da teoria freudiana, porque sequer funda a si mesma a priori, ou até mesmo a fortiori, em relação ao processo da crítica.

Falta à sintomatologia do artigo de 1961 efetivar a devida mediação ao redor de seu objeto de problematização. Tamanha mediação não está 
autorizada a pretender substituir o modelo empírico-material, todavia, está totalmente voltada para fundá-lo filosoficamente. Essa fundação ocorre de maneira mediata e indireta, ou seja, submetendo o empírico ao transcendental, por meio de uma pesquisa a respeito dos princípios. Em outros termos, Deleuze transforma a sintomatologia numa crítica portadora de coordenadas transcedendentais capaz de fundar e fundamentar a si mesma, independentemente do modelo empírico-material.

Com isso, a crítica portadora de coordenadas transcendentais é a pesquisa apresentada por Deleuze em Sacher-Masoch - o frio e o cruel, de 1967. Essa investigação tem por propósito desenvolver o projeto Crítica (literária) e Clínica (médica), que pode ser caracterizado, nesse primeiro momento, pela busca dos elementos diferenciais entre as obras de Sade e Sacher-Masoch, bem como, respectivamente, do sadismo e do masoquismo.

O traço distintivo marcante da crítica de modelo transcendental está associado à apresentação e ao uso da noção denominada "Instinto de morte" (DAVID-MÉNARD, 2014). Cabe à sintomatologia transcendental operacionalizar o Instinto de morte, para fins de fundamentação de uma pesquisa transcendental acerca da gênese do ato de pensar no próprio pensamento e do fenômeno do psiquismo.

Nesse sentido, o problema central de Sacher-Masoch - o frio e o cruel consiste no seguinte: tomando como base a unidade sadomasoquista, em que medida é possível resgatar os elementos diferenciais e as originalidades artísticas inerentes aos valores literários de Sade e Sacher-Masoch? A hipótese de Deleuze para solucionar esse problema é dotada de um aspecto crítico e de uma seara propositiva.

O aspecto crítico postula que a entidade sadomasoquista é uma síndrome, na qual ocorre a junção ou cruzamento entre linhagens causais bem distintas, oriundas de contextos variáveis. O núcleo dessa entidade é composto por uma unidade dialética decorrente de uma reflexão clínica sobre o sadismo, que, por sua vez, faz uso da reflexão literária a respeito de Sade. O efeito disso é que Sacher-Masoch passa a ser tratado como uma complementaridade em relação a Sade, dentro dessa unidade dialética.

A seara propositiva defende que há várias diferenças entre Sade e Sacher-Masoch. Essas distinçóes se referem às técnicas literárias, aos problemas, às preocupaçóes e ao projeto geral de cada um. Assim, Deleuze 
propóe reconsiderar as relações entre as obras de Sade e Sacher-Masoch, a partir de um ponto de vista literário, situado fora da clínica.

Esse ponto de vista deve estabelecer relaçôes entre a crítica literária e a clínica médica que sejam capazes de identificar os vínculos entre as especificidades clínicas do sadismo e do masoquismo junto, respectivamente, aos valores literários de Sade e Masoch. Portanto, no "Prólogo" de SacherMasoch - o frio e o cruel, Deleuze (2009, p. 14) caracteriza a sintomatologia como algo que sempre diz respeito à arte: "A sintomatologia diz sempre respeito à arte."

Naquilo que se liga ao Instinto de morte, é oportuno destacar pelo menos dois tópicos integrantes do livro de Sacher-Masoch - o frio e o cruel. O primeiro deles é intitulado de "O papel das descriçôes" e o segundo é denominado "O que é o Instinto de morte?” Há uma relação gradativa entre esses dois momentos, visto que, no primeiro, a noção de Instinto de morte é mencionada e, no segundo, ela é caracterizada com maiores detalhes, do ponto de vista de uma teoria dos princípios.

Em “O papel das descriçôes”, Deleuze afirma que, em Além do princípio de prazer, Freud faz a distinção entre pulsôes de vida e pulsôes de morte, Eros e Tânatos. Em seguida, Deleuze apresenta a objeção de que esse dualismo focalizado por Freud só pode ser compreendido através de outra distinção mais profunda, na qual estão opostas as pulsóes de morte e o Instinto de morte.

Deleuze sustenta que as pulsões de morte são dadas ou apresentadas, no inconsciente, sempre como estando misturadas às pulsóes de vida. Isso significa que a combinação com Eros é condição para a "apresentação" de Tânatos. Por conseguinte, Deleuze assevera que a destruição ou o negativo, na destruição, está presente necessariamente como o inverso de uma construção ou de uma unificação submetida ao princípio do prazer.

Como decorrência disso, Deleuze compreende a posição de Freud em defender que o "Não", enquanto negação pura, não está no inconsciente, porque as pulsóes contrárias, integrantes da perspectiva dualista, estão coincidindo no mesmo lugar. O Instinto de morte é Tânatos em estado puro, o qual não pode ser dado na vida psíquica, inclusive no inconsciente. Entretanto, Deleuze insiste que Tânatos dever ser mencionado, uma vez que ele é determinável como fundamento da vida psíquica, mesmo sem estar presente no interior dela. 
Ocorre que Deleuze retoma a advertência de Freud sobre a menção do Instinto de morte ou Tânatos. Dentro das exigências dessa advertência, a "menção" ao Instinto de morte necessita ser "especulativa" ou "mítica". Já a designação dever ser realizada por meio da palavra "Instinto", cujo propósito consiste em sugerir seu funcionamento enquanto princípio transcendental da vida psíquica.

Por sua vez, naquilo que concerne ao tópico "O que é o Instinto de morte?", Deleuze reinicia seu percurso, retomando Além do princípio de prazer (SANCHES, 2014). Além disso, argumenta que esse texto pode ser considerado uma obra prima do criador da psicanálise, pois, nessa ocasião, tem-se uma reflexão propriamente filosófica dotada de pura genialidade. Deleuze chama essa reflexão de "transcendental", visto que esse nome designa uma maneira de abordar a filosofia, através do tema dos princípios:

De todos os textos de Freud, é dúvida na obra-prima Além do princípio de prazer que ele penetra o mais diretamente, e com que genialidade, numa reflexão propriamente filosófica. A reflexão filosófica deve ser chamada "transcendental": esse nome designa uma certa maneira de considerar o problema dos princípios (DELEUZE, 2009, p. 102).

Desse modo, Deleuze afirma que o termo "além", para Freud, não diz respeito às exceções ao princípio de prazer, já que todas essas exceções (desprazeres e desvios que a realidade impóe, distúrbios funcionais e os fenômenos de transferência, dentre outros) são aparentemente conciliáveis com o princípio de prazer. Deleuze postula que não existem exceçôes ao princípio de prazer, mas que há singulares complicaçôes pertinentes ao prazer.

Deleuze advoga que é precisamente nesse ponto que tem início o problema filosófico, pois, caso nada contradiga ao princípio do prazer, isso não significa que tudo está reconciliado com ele. Em outros termos, Deleuze postula que, se tudo entra na regularidade do princípio do prazer, não significa que tudo possa sair dele. Portanto, Deleuze entende que o princípio do prazer reina sobre tudo, entretanto, náo governa tudo.

O pressuposto contido no argumento de Deleuze consiste em interpretar "Além", do Além do princípio de prazer, como "Fundação", logo "Além do princípio de prazer" torna-se "Fundação do princípio de prazer". Essa operação realizada por Deleuze quanto aos pressupostos permite a transformação no seu percurso e, em particular, no uso do modelo junguiano, 
pois, nesse momento, a crítica de coordenadas transcendentais é capaz de fundar a si mesma.

O corolário disso autoriza Deleuze a afirmar que, mesmo não havendo exceção ao princípio do prazer, existe um resíduo irredutível ao princípio, do qual decorre a ideia de que nada é contrário ao princípio, todavia, há algo exterior e heterogêneo em relação ao mesmo, cujo núcleo corresponde a um “Além”. Como decorrência disso, Deleuze entende que há a necessidade de uma reflexão propriamente filosófica, ou seja, uma pesquisa especulativa acerca dos princípios.

De acordo com Deleuze, em primeiro lugar, princípio é aquilo que rege ou regula um domínio. Esse tipo de princípio recebe o nome de "princípio empírico" ou "lei". Então, o princípio do prazer rege por completo a vida psíquica no "Id" ou "isso". No entanto, Deleuze explica que existe outro problema, o qual equivale à relação entre domínio e princípio, mais particularmente a sujeição do "domínio" ao "princípio".

Para investigar esse problema é necessário outro tipo de princípio, o qual Deleuze denomina "princípio de segundo grau". Esse princípio de segundo grau tem a função de explicar e sustentar a submissão necessária do "domínio" ao "princípio empírico", o qual pode ser considerado princípio de primeiro grau. Assim, o princípio de segundo grau é o princípio transcendental, que está voltado para assegurar a submissão do domínio ao princípio empírico, isto é, segundo Deleuze, o prazer é o princípio empírico que rege a vida psíquica enquanto domínio.

Estabelecido isso, o argumento de Deleuze retorna sua atenção para o tema daquilo que permanece exterior e heterogêneo ao princípio de prazer. Semelhante resíduo é o "valor" de princípio que o prazer está determinado a adotar, no interior da vida psíquica. Com base nisso, Deleuze recoloca o problema: qual é a ligação superior que faz do prazer um princípio, que lhe fornece o status de princípio e lhe sujeita o conjunto do psiquismo?

Para solucionar essa interrogação, Deleuze modifica os pressupostos da mesma. Sua transformação consiste em compreender o problema freudiano, náo com base no tema das exceçôes ao princípio do prazer, porém, enquanto fundação do princípio do prazer. Por isso, é um problema de especulação que, na leitura de Deleuze, culmina na descoberta de um princípio transcendental: "O que se segue é especulação, amiúde especulação forçada, que o leitor tomará em consideração ou porá de lado, de acordo com sua predileção 
individual. É mais uma tentativa de acompanhar uma ideia sistematicamente, só por curiosidade de ver até onde ela levará” (FREUD, 1976/1920, p. 39).

Quanto a esse ponto, o percurso de Deleuze adota para si a resposta de Freud, segundo a qual é a ligação da excitação que faz com que ela seja resolvida em prazer: "[...] a vinculação da energia que flui para dentro do aparelho mental consiste em sua mudança de um estado de fluxo livre para um estado quiescente" (FREUD, 1976/1920, p. 47).

É a ligação que torna possível a descarga do prazer. Deleuze afirma que, sem a atividade de ligação, não haverá valor sistemático na descarga de prazer. Podem, inclusive, ocorrer descargas esparsas ou ao acaso, todavia, isentas de valor sistêmico. Logo, a ligação funda o princípio do prazer.

Enquanto decorrência desse ponto, Deleuze sustenta que Eros está descoberto como fundamento composto por uma dupla ligação: ligação energética da excitação e ligação biológica das células. Essa dupla ligação constitutiva de Eros Deleuze nomeia de "repetição". Tamanha repetição acomete a dupla face da ligação: repetição com relação à excitação e repetição no momento da vida.

Aí temos, então, Eros descoberto como fundamento, sob a dupla figura da ligação: ligação energética da própria excitação, ligação biológica das células (é possível que a primeira só ocorra através da segunda, ou nela encontre condiçóes particularmente favoráveis). E nós podemos e devemos determinar essa ligação constitutiva de Eros como "repetição": repetição com relação à excitação; repetição do momento da vida, ou união necessária até para unicelulares (DELEUZE, 2009, p. 112).

Conforme Deleuze, essa descoberta de Eros constituído pela dupla face da ligação, ou da repetição, caracteriza a pesquisa como transcendental. Nos limites de nosso trabalho, denominamos essa pesquisa "crítica portadora de elementos transcendentais", a qual não pode ser interrompida quando se quer ou a qualquer momento. Essa força necessária, inerente à crítica transcendental, oportuniza que Deleuze radicalize o problema e alcance a seguinte formulação: em que medida é possível pesquisar e determinar um fundamento, sem vir a ser precipitado no sem-fundo do qual ele emerge?

Deleuze não só reconhece a dificuldade relativa a esse problema, como também assevera que o coração de sua formulação consiste no seguinte: de que maneira a excitação seria ligada e resolvida, se a mesma força que a liga 
não possuísse igualmente a tendência a negá-la? É prudente desemaranharmos um pouco a sofisticação do problema colocado por Deleuze, para fins de elucidação. Ora, se Eros desempenha o papel de ligar ao mesmo tempo a excitação e a vida, como ele também poderia atuar antes de realizar essa dupla ligação, preservando outro ritmo e outro desempenho?

Deleuze nos transmite a impressão de que estamos diante de um limite de Eros ou da dupla ligação, ou da própria repetição. Para ultrapassar esse limite, Deleuze defende que existe outra repetição, a qual corresponde à imagem de uma "borracha", cujo propósito consiste em apagar e matar. Assim, para Deleuze, existem duas repetiçóes: a repetição-laço ou Eros e a repetição-borracha ou Tânatos (MONTEBELLO, 2011), o qual corresponde ao sem-fundo: "Além de Eros, Tânatos, Além do fundo; o sem-fundo. Além da repetição-laço, a repetição-borracha, que apaga e que mata" (DELEUZE, 2009, p. 112).

Esse encontro com Tânatos a partir de Eros faz com que o percurso de Deleuze realize seu passo posterior, o qual diz respeito à compreensão da repetição enquanto síntese do tempo. Deleuze entende a síntese do tempo como "síntese transcendental do tempo". Essa síntese é, simultaneamente, repetiçáo do antes, do durante e do depois, constituindo o tempo passado, o presente e o futuro.

Posto isso, o argumento constitutivo do percurso de Deleuze volta sua atenção para a relação entre experiência e repetição. Segundo Deleuze, a repetição, a qual, no fundo e no sem-fundo, precede o princípio do prazer, é vivenciada como tendo sido subvertida e subordinada e esse princípio. Acerca disso, os resultados da sintomatologia transcendental, são que Eros é o que torna possível a instauração do princípio empírico do prazer, porém, arrastando sempre Tânatos consigo.

Sobre isso, Deleuze assevera que Eros e Tânatos não podem ser dados ou vivenciados. Na experiência, existe uma combinação entre os dois, na qual a função de Eros consiste em ligar a energia de Tânatos e submeter essas combinaçôes ao princípio enseja que ele seja "escutado" e entre em "ação". Por outro lado, Tânatos, que corresponde ao sem-fundo, é carregado por Eros e, por consequência, é também trazido à superfície. Além disso, Tânatos é essencialmente silencioso e, marcadamente, mais terrível.

Esse segmento do percurso de Deleuze possibilita que ele realize a distinção, do ponto de vista da sintomatologia transcendental, entre "Instinto" 
e "pulsão". Nesse sentido, o "Instinto de morte" é a instância transcendente e silenciosa que pode assustar e, até mesmo, danificar Eros por conta de sua ininterrupta força que clama por ascensão e distribuição. Já as "pulsões de morte" designam os representantes diretos de Eros e os representantes indiretos de Tânatos, sempre misturados no "isso". Portanto, Tânatos sempre "é", mas nunca há o "não" no inconsciente, visto que a destruição é dada como o inverso da construção.

\section{Consideraçóes Finais}

É oportuno retomarmos o objetivo de nosso trabalho: explicitar o percurso entre duas leituras que Gilles Deleuze realiza acerca da obra de Sacher-Masoch. A primeira leitura concerne ao artigo de 1961, intitulado "De Sacher-Masoch ao masoquismo. A segunda leitura, por sua vez, diz respeito ao livro de 1967, intitulado de Sacher-Masoch - o frio e o cruel.

Argumentamos, enquanto hipótese de leitura, que a relação entre esses dois momentos é constituída por um processo de radicalização transcendental, por parte do pensamento de Deleuze. Esse processo adota como ponto de partida a sintomatologia junguiana exposta no artigo de 1961 e encontra seu termo na crítica portadora de coordenadas transcendentais, explicitada no livro de 1967, através do conceito de "Instinto de morte" e do processo de fundação do prazer enquanto princípio.

Naquilo que tange à sintomatologia, de um ponto de vista das tensóes, continuidades e rupturas, é possível identificar entre "De Sacher-Masoch ao masoquismo" e Sacher-Masoch - o frio e o cruel uma mudança no modelo crítico. A mudança no modelo ocorre quando, no livro de 1967, Deleuze busca por uma fundação transcendental para o prazer enquanto princípio, reduzindo, assim, a relevância do modelo imagético-simbólico, pois este possui limites para sustentar filosoficamente a si mesmo, embora sua crítica ao modelo material e empírico seja dotada de pertinência.

Por fim, do ponto de vista dos resultados, é possível afirmarmos que o percurso que vai da sintomatologia de modelo junguiano à crítica portadora de coordenadas transcendentais corresponde ao esforço do pensamento de Deleuze em assegurar uma problematização filosófica e crítica, a respeito das relaçóes entre a vivência ativa do ato de pensar e a psicanálise. 
FREITAS, F. L. C.; FAÇANHA, L. S. From the symptomatology of the jungian model to the critique of transcendental coordinates: a reading about Deleuze's Sacher-Masoch. Trans/form/ ação, Marília, v. 43, n. 4, p. 183-202, Out./Dez., 2020.

\begin{abstract}
: the general objective of the present work is to explain the course between two readings that Gilles Deleuze realizes about the work of Sacher-Masoch in the 60's of the 20th century. The first reading concerns the 1961 article From Sacher-Masoch to masochism. The second reading concerns the 1967 book entitled Sacher-Masoch - the cold and the cruel. It is postulated that the relation between these two moments is constituted by a process of transcendental radicalization on the part of Deleuze, which goes from the symptomatology of Jungian model until reaching the transcendental criticism.
\end{abstract}

Keywords: Deleuze. Sacher-Masoch. Jung. Symptomatology. Transcendental.

\title{
REFERÊNCIAS
}

ALLIEZ, E. Deleuze avec Masoch. In: Deleuze et les écrivains. Littérature et Philosophie. Nantes: Éditions Cécile Default, 2007

DAVID-MÉNARD, M. Deleuze e a psicanálise. Tradução de Marcelo Jacques de Moraes. Rio de Janeiro: Civilização Brasileira, 2014

DELEUZE, G. Conversaçóes. Tradução de Peter Pál Pelbart. São Paulo: Editora 34, 1992.

DELEUZE, G. Diferença e repetiçáo. Tradução: Roberto Machado e Luiz Orlandi. Rio de Janeiro: Graal, 2006.

DELEUZE, G. Mística e Masoquismo. Traduzido por Fabien Lins. In: A ilha deserta e outros textos: textos e entrevistas (1953 - 1974). Edição preparada por David Lapoujade. São Paulo: Editora Iluminuras, 2006

DELEUZE, G. Sacher-Masoch - o frio e o cruel. Tradução de Jorge Bastos e revisão técnica de Roberto Machado. Rio de Janeiro: Zahar, 2009

DELEUZE, G. Du Sacher-Masoch au Masochisme. In: LAPOUJADE, D. Lettres et Autres Textes. Paris: Les Éditions de Minuit, 2015/1961.

DOSSE, F.Gilles Deleuze e Félix Guattari: biografia cruzada. Tradução de Murad. Porto Alegre: Artmed, 2010.

FREITAS, F. Do grito do incondicionado aos ruídos do tempo: Gilles Deleuze e a questão do princípio do prazer. Revista Dois Pontos, São Carlos/Curitiba, v. 13, n. 03, p.187-209, dez; 2016. Disponível em: https://revistas.ufpr.br/doispontos/article/ view/46917. Acesso em: 09/12/2017 
FREUD, S. Além do princípio de prazer. Tradução de Jayme Salomão. Rio de Janeiro: Imago Editora, 1976/1920.

JUNG. C.G.. Os arquétipos e o inconsciente coletivo. Tradução Maria Luíza Appy e Dora Mariana Ferreira da Silva. Editora Vozes: Petrópolis, 2000/1969.

MONTEBELLO, P. L'instinct de mort chez Deleuze La controverse avec La psychanalyse. Revista Dois Pontos. Curitiba/São Carlos: volume 8, número 2, p. 15-26, out; 2011. Disponível em: https://revistas.ufpr.br/doispontos/article/view/21932 . Acessado em: 10/12/2017.

SACHER-MASOCH, L.v. A vênus das peles. Tradução de Saulo Krieger. São Paulo: Editora Hedra, 2015.

SANTIAGO, H. Deleuze leitor de Masoch: Da sintomatologia à ética. In: Deleuze hoje. Edição coordenada por Sandro Kobol Fornazari e organizada por Adriana Barin de Azevedo, Bárbara Lucchesi Ramacciotti, Cíntia Vieira da Silva, Cleber Daniel Lambert da Silva. São Paulo: Editora Fap -Unifesp, 2014.

SANCHES, A. A importância de pensar o além do princípio de prazer na filosofia transcendental: diálogos entre Deleuze e Freud. In: AZEVEDO, A. B. de et al. (Orgs.). Deleuze hoje. São Paulo: Editora Fap-Unifesp, 2014.

Recebido: 14/01/2019

Aceito: 23/02/2020 